\title{
SOBRE LA CONSTITUCIONALIDAD DE UNA REFORMA CONSTITUCIONAL
}

\author{
IMER B. FLORES*
}

The legitimacy of a constitutional reform depends on the path it followed to be approved. For this reason, it is necessary then to be aware of the forms and limits of legislation and constitutional reforms, in order to not forget that such reforms should have gone through the same restrictions that apply to legislative processes. The article states these conditions that must be observed in the creation of laws and constitutions, and also presents reasons that create additional limits to constitutional reforms, as for example, improper venues.

\section{Introducción}

Tomar la Constitución en serio implica adoptar, entre otros, el principio de la supremacía constitucional por encima de la mera primacía legal. En palabras de Gustavo Zagrebelsky: el Estado constitucional sobre el Estado de derecho legislativo. ${ }^{1}$ De esta forma, es un lugar común afirmar que es necesario revisar que las leyes se ajusten a lo dispuesto por la Constitución -e inclusive por los tratados internacionales en materia de derechos humanos como parte del bloque de constitucionalidad- y no viceversa. Esto es lo que comúnmente conocemos como control constitucional o de la constitucionalidad de las leyes.

"El autor agradece al magistrado Humberto Sierra Porto el haber intercambiado impresiones sobre las ideas contenidas en la última parte de este texto.

${ }^{1}$ Zagrebelsky, Gustavo, El derecho dúctil. Ley, derechos, justicia, Madrid, Trotta, 1997, (pp. 2145). 
De esta forma, como garantía indirecta de la supremacía constitucional, se ha optado además por un procedimiento difícil de reforma, el cual permite salvaguardar su estabilidad o permanencia al mismo tiempo que no cancela la posibilidad de cambio. ${ }^{2}$ Ahora bien, la cuestión pendiente es saber si las reformas constitucionales son objeto del control constitucional o no. Adelanto que para mí sí lo son, aunque todavía debemos precisar en qué casos y en qué condiciones. Para ello, en esta ocasión abordo dos temas: las formas y los límites de la legislación, en general, y de la reforma constitucional, en particular. El primero tiene por objeto identificar la reforma constitucional dentro de las formas de legislación y en consecuencia sugerir que ésta -la reforma constitucional- está sujeta a los mismos límites que el resto de las formas de legislación. La segunda tiene por objeto desarrollar el argumento esbozado en la primera parte al precisar cuáles son los límites de la reforma constitucional.

\section{Las formas y los límites de la legislación ${ }^{3}$}

Antes que nada, cabe advertir que esta ponencia se inscribe en una de mis líneas de investigación, conocida como 'legisprudencia', i.e. "La teoría y la práctica de la legislación”. Ahora bien, como la palabra 'legislación' está afectada por la ambigüedad proceso-resultado, debemos aclarar que ésta -la 'legisprudencia'- comprende el estudio no sólo del "proceso legislativo", es decir del "legislar", sino también del "resultado legislativo", esto es de la "ley". Así mismo, connota el examen del "legislador" y de la "legislatura". ${ }^{4}$ De igual forma, debemos clarificar que si bien el término 'legislación' se usa, por lo general, en

${ }^{2}$ Flores, Imer B, "Heráclito vis-à-vis Parménides: Cambio y permanencia como la principal función del derecho en una democracia incipiente”, en: Molina Piñeiro, Luis, J. Fernando Ojesto Martínez y Fernando Serrano Migallón (cords.), Funciones del derecho en las democracias incipientes. El caso de México, Porrúa y Facultad de Derecho UNAM, México, 2005, pp. 149-171.

${ }^{3}$ Este apartado tiene sus antecedentes inmediatos en: Flores, Imer B, "Legisprudence: the Forms and the Limits of Legislation", ponencia presentada en el Special Workshop Legisprudence, en el XXII IVR World Congress en Granada, España, del 24 al 29 de mayo de 2005; y mediatos en: Fuller, Lon L., "The Forms and Limits of Adjudication", en: The Principles of Social Order, Durham, North Carolina, Duke University Press, 1981, p. 87. (Publicación original: Harvard Law Review, Vol. 92, 1978, p. 357.)

${ }^{4}$ Flores, Imer B, "The Quest for Legisprudence: Constitutionalism v. Legalism", en: Witgens, Luc J. (ed.), The Theory and Practice of Legislation. Essays in Legisprudence, Aldershot, Ashgate, Hampshire, 2005, p. 26. 
un sentido estricto para denotar tanto la actividad que realiza el legislador en la legislatura como el producto resultante de ella, además se utiliza en un sentido amplio para designar cualquier proceso o resultado legislativo: desde los padres que asumen el rol del legislador para establecer principios fundamentales o reglas básicas para sus hijos (para "legislar leyes", valga la redundancia), hasta quienes lo hacen para promulgar una Constitución y su eventual enmienda o reforma, incluida la celebración de un tratado internacional o de un acuerdo interinstitucional, los reglamentos del poder ejecutivo y los acuerdos generales del poder judicial y del poder legislativo; siempre y cuando el producto o resultado sea una norma general, abstracta, impersonal y permanente, con independencia del nombre que reciba.

Así, el vocablo 'legislación' como lo empleamos no está reservado solamente a los legisladores y las legislaturas que forman parte de lo que conocemos como poder legislativo, sino para todos aquellos que formulan normas generales, abstractas, impersonales y permanentes. De tal suerte, incluimos tanto a las asambleas legislativas que promulgan leyes como a los agentes o cuerpos que asumen atribuciones legislativas, ya sea para promulgar una Constitución, o para enmendarla o reformarla; para adicionar o modificar, de un lado, y para abrogar o derogar, del otro, una ley; para celebrar un tratado internacional, regional o bilateral, e incluso un acuerdo interinstitucional; para expedir un reglamento, etcétera.

\section{Formas}

Por "formas" de la legislación entendemos las maneras legítimas en que ésta se puede organizar y realizar. Tratamos así de diferenciar cuáles son las formas permitidas o propias de la legislación y cuáles no lo son. Por una parte, las formas permitidas o propias de la legislación son aquellos productos o resultados que son verdaderamente generales, abstractos, impersonales y permanentes, independientemente del agente o cuerpo que asume las atribuciones legislativas, siempre y cuando éste actúe de acuerdo con los principios de la racionalidad jurídica y esté autorizado para hacerlo.

\footnotetext{
${ }^{5}$ En este punto seguimos a Manuel Atienza, quien afirma que los principios de racionalidad jurídica son los mismos tanto para la adjudicación como para la legislación, a saber: racionalidad lingüística (R1); racionalidad lógico-formal o sistemática (R2); racionalidad pragmática (R3); racionalidad teleológica (R4); y racionalidad ética (R5). Véase: Atienza, Manuel, "Sociología jurídica y ciencia de la legislación", en: Bergalli R., (ed.), El derecho y sus realidades. Investigación y enseñanza de la sociología jurídica, PPU, Barcelona, 1989, pp. 41-70; "Contribución a la teoría de la legislación", Doxa, Vol. 6, 1989, pp. 385-403; Contribución a la teoría de la legislación, Tecnos, Madrid, 1997; "Reasoning and Legislation", en: Witgens, Luc J. (ed.), The Theory and Practice of Legislation. Essays in Legisprudence, Aldershot, Ashgate, Hampshire, 2005, pp. 297-317. Véase también: Flores, 2005: 37-38, y "Legisprudence: the Forms and the Limits of Legislation", cit. en la nota 3.
} 
Por esta razón entre las variantes de la legislación, además del caso obvio de una asamblea legislativa que promulga una ley o decreto, están:

1. Una asamblea constituyente que promulga una Constitución.

2. Una asamblea legislativa extraordinaria que como órgano o poder revisor la Constitución enmienda o reforma una Constitución.

3. Una asamblea legislativa ordinaria que adiciona o modifica, de un lado, y abroga o deroga, del otro, una ley.

4. Un jefe de Estado -o cualquier autoridad- que celebra junto a sus similares un tratado internacional, regional o bilateral, e incluso un acuerdo interinstitucional.

5. Un jefe de gobierno -o los responsables o titulares de alguno de los poderes u órganos autónomos del Estado- que formula un reglamento, acuerdo general o memorando.

Por otra parte, las formas pervertidas o impropias de la legislación son aquellos productos o resultados que no son verdaderamente generales, abstractos, impersonales y permanentes, independientemente del agente o cuerpo que asume las atribuciones legislativas, porque éste no actúa de acuerdo con los principios de la racionalidad jurídica o no está autorizado para hacerlo.

El caso problemático es el de la llamada "legislación judicial", i.e. la idea de que en ciertas circunstancias excepcionales los jueces legislan o al menos lo hacen de manera intersticial, de cuando en cuando, como lo aceptó Oliver Wendell Holmes: "Reconozco sin duda alguna que los jueces legislan y deben legislar, pero solamente pueden hacerlo intersticialmente". "O tal como lo admitió Herbert Louis A. Hart, al señalar que dada la "textura abierta del lenguaje", en algunos casos, los jueces inevitablemente tienen que ejercer su discreción y al hacerlo asumen el papel del legislador para crear derecho intersticialmente: "Las normas jurídicas exigen interpretación para ser aplicadas a los casos concretos, y una vez que el estudio realista disipa los mitos que oscurecen la naturaleza de los procesos judiciales, se hace patente[...] que la textura abierta del derecho deja un vasto campo para una actividad creadora

\footnotetext{
${ }^{6}$ Southern Pacific v. Jensen, 244 U.S. 205, 221 (1917): "I recognize without hesitation that judges do and must legislate, but they can do so only interstitially". (La traducción es propia.)
} 
que algunos llaman legislativa". ${ }^{7} \mathrm{Al}$ respecto habría que decir tres cosas:

1. Los jueces no están autorizados para legislar, i.e. hacer la ley o ius dare, sino para interpretar y aplicar la ley general a un caso particular y en consecuencia adjudicar derechos y deberes.

2. La función primaria y propia de los jueces es adjudicar, i.e. encontrar la ley aplicable para adjudicar derechos y deberes o ius iudicare.

3. Los jueces inevitablemente tienen que asumir otras funciones secundarias pero todavía propias, para alcanzar su función primaria y propia, tales como:

a. interpretar la ley o la norma para atribuirle un sentido o significado o ius dicere;

b. integrar-ante las llamadas "lagunas"- la ley o la norma aplicable a un caso no previsto a partir de analogías con otras leyes o normas - analogia legis-, caracterizada como autointegración o integratio legis, y a falta de éstas con los principios generales del derecho - analogia iuris-, conocida como heterointegración o integratio iuris; y

c. argumentar, i.e. dar razones a favor o en contra de una u otra inter-

${ }^{7}$ Hart, H. L. A., The Concept of Law, Oxford University Press, 1961, p. 200: "Laws require interpretation if they are to be applied to concrete cases, and once the myths which obscure the nature of the judicial processes are dispelled by realistic study, it is patent... that the open texture of law leaves a vast field for a creative activity which some call legislative." (Hay versión en español: El concepto de derecho, trad. Genaro R. Carrió, Buenos Aires, Abeledo-Perrot, 1963, p. 252.) (Hay 2a edición con "Postscript", 1994, p. 205; y versión en español: Post scriptum a El concepto de derecho, trad. Rolando Tamayo y Salmorán, México, Instituto de Investigaciones Jurídicas, 2000.) Cfr. Hart, H. L. A., "American Jurisprudence through English Eyes: The Nightmare and the Noble Dream", en: Essays in Jurisprudence and Philosophy, Oxford, Clarendon Press, 1983, p. 128. (Hay versión en español: "Una mirada inglesa a la teoría del derecho norteamericana: la pesadilla y el noble sueño”, trad. José Juan Moreso y Pablo Eugenio Navarro, en: Casanovas, Pompeu y José Juan Moreso (eds.), El ámbito de lo jurídico. Lecturas de pensamiento jurídico contemporáneo, Crítica, Barcelona, 1994, pp. 327-350.) (Publicación original: Georgia Law Review, Vol. 11, No. 5, 1977.)

${ }^{8}$ En el contexto de la polémica entre el rey James I -castellanizado Jacobo I- y Sir Edward Coke -o Cook- en la cual éste en su calidad de juez advertía que aquél por más monarca o soberano que fuera no tenía un poder ilimitado, Sir Francis Bacon escribió uno de sus celebérrimos ensayos, "Sobre la judicatura", que comienza con una recomendación: "Los jueces jamás deben olvidar que su oficio es jus dicere y no jus dare; es decir, que su oficio es interpretar y aplicar la ley, y no hacerla o imponerla como comúnmente se dice". Bacon, Francis, "Of Judicature”, Essays, Everyman, London, 1994, p. 141. (Hay versión en español: "Sobre los deberes de los jueces" en Ensayos sobre moral y política, trad. Arcadio Roda Rivas, Universidad Nacional Autónoma de México, 1974, p. 226.) Ver también: Flores, 2005: 43-45.

9 "El ámbito propio de la adjudicación es tomar determinaciones autoritativas acerca de las preguntas formuladas por disputas de derechos y acusaciones de culpa o dolo". (Fuller, 1981: 96) (La traducción es propia). 
pretación o integración, no sólo para justificar su decisión sino también para convencer o persuadir sobre su corrección formal y material. ${ }^{10}$

No critico el hecho de que los jueces puedan crear derecho, ya sea al crear - como diría Hans Kelsen- la solución al caso concreto, es decir la norma individualizada: " $x$ está condenado a pagarle a $y$, porque es responsable de $z$ "; ni que al hacerlo puedan crear un precedente, esto es, un criterio o modelo de interpretación y hasta de integración para casos futuros: "Cuando alguien como $x$ es responsable de $z$-o de algo comparable a $z$ - será condenado a pagarle a alguien como $y$ ".

Lo que cuestiono son dos cosas: primera, la idea de que los juzgadores legislan o bien que deban o puedan legislar, i.e. crear normas generales, abstractas, impersonales y permanentes, no la idea de que crean derecho de alguna forma, ya sea una norma individualizada, de un lado, o un criterio o precedente, del otro; y, segunda, la idea de que como lo hacen de modo intersticial, de vez en vez, como excepción, pueden actuar de la nada como si fueran ellos mismos los legisladores, lo cual no sería otra cosa sino una verdadera "usurpación judicial". Es más, actuar de la nada ni siquiera un legislador puede hacerlo, porque ello representaría no respetar los límites explícitos e implícitos de sus funciones, en general, y los derechos humanos y la división de poderes, así como los principios de la racionalidad jurídica, en particular. Por el contrario, el juez deriva o desarrolla, a partir de las normas generales y de los principios generales del derecho, una decisión para el caso particular ante él que sirve además de criterio o precedente para casos futuros, pero no una nueva norma general con lo cual suplantaría al legislador. Al respecto, tal y como Lon L. Fuller aclaró: "La corrección de obvios errores

${ }^{10}$ Flores, Imer B., "Apuntes para una teoría - y práctica - del derecho judicial: Algunas reflexiones críticas sobre técnica jurídica”, Reforma judicial. Revista Mexicana de Justicia, No. 7, enero-junio, 2006, pp. 3-25.

${ }^{11}$ "Por más que pueda distinguirse, la diferencia entre la función jurisdiccional y la función legislativa consiste, ante todo, en que ésta crea normas jurídicas generales, en tanto que la otra no crea sino normas individuales". Kelsen, Hans, La garantía jurisdiccional de la Constitución. (La justicia constitucional), trad. Rolando Tamayo y Salmorán, Universidad Nacional Autónoma de México, 2001, p. 54.

${ }^{12}$ Cfr. Fuller, Lon L., "The Case of the Speluncean Explorers", Harvard Law Review, Vol. 112, No. 8, 1999, p. 1858. (Publicación original: 1949; y hay versión en español: El caso de los exploradores de cavernas, Genaro R. Carrío, Buenos Aires, Abeledo-Perrot, 1961, p. 31.) (Reproducido en: Suber, Peter, The Case of the Speluncean Explorers. Nine New Opinions, Routledge, London, 1998, p. 14.) 
u omisiones legislativas no significa suplantar la voluntad del legislador, sino hacerla efectiva".

\section{Límites}

Por "límites" de la legislación entendemos las restricciones explícitas e implícitas propias de las formas en que ésta se puede organizar y realizar. De este modo, en primerísimo lugar, tratamos de distinguir cuáles son las funciones que se pueden asignar propiamente a los legisladores y cuáles no. Lo anterior nos permitirá adelantar algunas luces acerca de los límites de la legislación.

Por una parte, las funciones propias asignadas a los legisladores dada su naturaleza representativa implican tomar decisiones políticas - por definición, ideológicas, pero no necesariamente subjetivas- o dependientes de consideraciones políticas, como sería el caso de si el electorado está o no de acuerdo con el producto o resultado de la legislación. En este sentido, estas decisiones políticas que afectan a clases o grupos de personas no se relacionan solamente con la discusión y aprobación de las reformas constitucionales, de las leyes y de sus adiciones o modificaciones y de la ratificación de los tratados internacionales celebrados por el Presidente de la República. También implican funciones de colaboración y control en relación con otros poderes, órganos o actores, tales como la aprobación del presupuesto y la fiscalización del gasto público. ${ }^{14}$

Por otra parte, hay funciones impropias para ser realizadas por los legisladores porque implican decisiones técnicas, las cuales si bien no son necesariamente apolíticas sí son independientes de consideraciones políticas, sin importar si el electorado está o no de acuerdo con la decisión tomada. Es más, por definición las decisiones de los jueces deben ser imparciales o, lo que es lo mismo, técnicas, no políticas. Aunado a lo anterior, los problemas jurídicos que H. L. A. Hart caracterizó como de la "textura abierta del lenguaje", tales como la ambigüedad y la vaguedad, así como las antinomias y lagunas, los conflictos de reglas y las colisiones de principios, son resueltos de manera técnica y no de modo político.

\footnotetext{
${ }^{13}$ Fuller, 1999: 1859: "The correction of obvious legislative errors or oversights is not to supplant the legislative will, but to make that will effective".

${ }^{14}$ Por supuesto que el hecho de que estas decisiones sean primordialmente políticas, no quiere decir que algunas no sean a la vez técnicas - o tengan componentes técnicos - ni que no tengan que cumplir con los principios de racionalidad jurídica. Véase: Flores, 2005: 37-38; y "Legisprudence: the Forms and the Limits of Legislation", cit. en la nota 3. Véase también la ponencia de Cecilia Mora-Donatto presentada en este mismo Congreso.

${ }^{15}$ Cfr. Hart, 1961: 121-132 (155-169) (124-136).
} 
En este sentido, las decisiones dirigidas a individuos - no a clases o grupos de personas-, al igual que los precedentes, son decisiones técnicas y como tales no políticas. Esto es verdad porque per definitio las primeras no son ni pueden ser generales. Por su parte, los segundos, aunque son expresados en términos más o menos amplios y tienen algún grado de generalidad, no son una forma de legislación obligatoria para todos, tanto gobernantes como gobernados, sino un criterio o precedente de interpretación e incluso de integración para casos futuros con características particulares y concretas, obligatorias para algunos de los operadores jurídicos como son los jueces, pero no necesariamente para todos. Al grado tal que si el legislador está o no de acuerdo con el modelo o la pauta adoptada por el juzgador podrá ratificarla o reformarla al legislar en la materia, siempre y cuando esté facultado para hacerlo.

El legislador, además de estar facultado para legislar -y, en su caso, para reformar la Constitución-y de seguir el procedimiento previsto para hacerlo, debe cumplir a cabalidad con "los principios de racionalidad jurídica" obedeciendo "las leyes implícitas de la legislación" o "la moralidad interna del derecho", ${ }^{16}$ y observando "los atributos esenciales y no-esenciales del bon législateur".

\section{Los límites de la reforma constitucional}

Tanto la promulgación de una ley como la realización de una reforma constitucional implican como actividad o proceso el tomar decisiones políticas, y como producto o resultado una norma general, abstracta, impersonal y permanente. Por ende, al final de cuentas, son encargadas a poderes $\mathrm{u}$ órganos que tienen una naturaleza democrática, electiva y representativa. En cambio, las decisiones técnicas como la del control de constitucionalidad son encomendadas a poderes u órganos que no participaron en dichos

\footnotetext{
${ }^{16}$ Véase: Fuller, Lon L., The Morality of Law, 2a ed., New Haven, Yale University Press, 1969, p. 39. (Hay versión en español de la 1ª ed.: La moral del derecho, Francisco Navarro, México, Trillas, 1967). "Implicit Elements in Made Law", en: The Anatomy of Law, Frederick A. Praeger, New York, 1968, pp. 91-110.

${ }^{17}$ Véase: Bobbio, Norberto "Le bon législateur", en : Hubien, Hubert (ed.), Le raisonnment juridique/Legal Reasoning/Die jurisdiche argumentation, Bruxelles, Établissements Émile Bruylant, 1971, pp. 243-249.
} 
procedimientos y que como tales pueden ser imparciales al decidir sobre éstas, en especial, porque son independientes de las presiones políticas.

Desde la célebre disputa entre Carl Schmitt y Hans Kelsen, la cual comienza con la publicación del libro de aquél Der Hütter der Verfassung -literalmente "El Protector de la Constitución"- y que continúa con la réplica de éste Wer soll der Hütter der Verfassung sein? -i.e. "¿Quién debe ser el Protector de la Constitución?" por lo general en poderes u órganos jurisdiccionales, a la sazón: en el poder judicial, ya sea en la Suprema Corte de Justicia de la Nación, como en el caso de México; en un Tribunal Constitucional, como en el caso de España; o bien, en lo que ha dado lugar a una fórmula mixta, en una Corte Constitucional o de Constitucionalidad, como en el caso de Colombia.

Hasta aquí, a partir de las semejanzas entre la promulgación de la ley y la realización de la reforma constitucional, no hay problema para concebir tanto a una como la otra como objeto de control constitucional. Ahora bien, las diferencias entre ambas parecen sugerir que el control de constitucionalidad de una reforma constitucional queda o puede quedar en entredicho. Al respecto, debemos traer a colación al menos dos distinciones:

La primera entre el titular de la facultad legislativa, es decir, el órgano o poder legislativo - un poder constituido-, y el de la facultad reformatoria, esto es, el órgano o poder revisor de la Constitución, el mal llamado "constituyente permanente", un poder constituido conformado por dos poderes constituidos, a saber: el legislativo y el federativo.

La segunda, entre el procedimiento en uno y otro caso. En México, aunque ambos parten del procedimiento legislativo ordinario, en la reforma

\footnotetext{
${ }^{18}$ Nótese que esto no quiere decir que los jueces no sean democráticos ni representativos por el simple hecho de no ser elegidos, lo cual es un hecho meramente contingente. Es más, ser elegidos no es condición necesaria ni mucho menos suficiente para ser democráticos o representativos. Cfr. Flores, Imer B., "Assessing Democracy and Rule of Law: Access to Justice”, en: Peczenik, Aleksander (ed.), Proceedings of the 21 ${ }^{\text {st }}$ IVR World Congress, Lund (Sweden), 12-17 August, 2003, Part I: Justice, Stuttgart, Franz Steiner Verlag, 2004, pp. 151-152; y "Constitución, democracia y derecho: teoría constitucional y valores constitucionales", Revista del Instituto de la Judicatura Federal, No. 15, 2003, pp. 150-153.

${ }^{19}$ Cfr. Schmitt, Carl, La defensa de la Constitución. Estudio acerca de las diversas especies y posibilidades de salvaguardia de la Constitución, trad. Manuel Sánchez Sarto, Editorial Labor, Barcelona, 1931; Kelsen, 2001.

${ }^{20}$ Cfr. Tena Ramírez, Felipe, Derecho constitucional mexicano, Porrúa, México, 1993, pp. 45-64.
} 
constitucional -como un procedimiento dificultado diferente al legislativo ordinario y como tal extraordinario, aunque ciertamente parte de aquél- se requiere además de una votación calificada de dos terceras partes, así como la mayoría (simple) de las legislaturas de los Estados.

Por una parte, en lo referente al mal llamado "poder constituyente permanente", también caracterizado como "poder constituyente constituido, derivado o instituido", para distinguirlo del "poder constituyente originario", habría que decir que ni es constituyente ni es permanente sino constituido. Al respecto, el mismísimo Felipe Tena Ramírez anota: "La separación en el tiempo del Poder Constituyente, autor de la Constitución, y de los Poderes constituidos, obra y emanación de aquél, no presenta dificultad; en el momento en que la vida del primero se extingue, por haber cumplido su misión, comienza la de los segundos. La diferenciación teórica tampoco es difícil de entender: el Poder Constituyente únicamente otorga facultades, pero nunca las ejercita, al contrario de los Poderes constituidos, que ejercitan las facultades recibidas del constituyente, sin otorgárselas nunca a sí mismos". ${ }^{22}$ No obstante, este mismo autor apunta que el poder u órgano reformador o revisor de la Constitución puede cumplir con una función constituyente. Su equívoco se explica pero no se justifica en el hecho de que distingue, además del "constituyente originario", un "constituyente reformador" -al que denomina "constituyente permanente"-y otro "constituyente revolucionario", los cuales en un momento dado podrían cambiar la Constitución vigente en su totalidad por una distinta.

Para reforzar la idea de que la naturaleza del poder u órgano reformador de la Constitución es siempre la de un poder constituido y nunca la de un constituyente, y que como tal no habría problema para que sea objeto de control por otro poder constituido, ofrecemos tres argumentos: En primera instancia, un poder constituyente, por definición, es aquél convocado ad hoc para crear una Constitución y para ordenar u organizar jurídicamente el poder, entre otras asignaciones. Así que una vez creada la Constitución y con ella los poderes u órganos del Estado, el poder constituyente originario desaparece. En segundo lugar, todos los poderes u órganos constituidos en de una Constitución -incluido el poder u órgano reformador de la misma- son,

${ }^{21}$ En los Estados Unidos de América, país del cual adoptamos o mejor dicho adaptamos la fórmula, para ratificar las enmiendas a la Constitución se requiere no de una mayoría simple de las legislaturas de los Estados sino de tres cuartas partes, tal y como lo consagra el Artículo V.

${ }^{22}$ Tena, 1993: 45.

${ }^{23}$ Tena, 1993: 45-64, 65-74. 
como el mismo nombre lo indica, "constituidos" y de ninguna forma pueden confundirse con el "constituyente". En tercer término, el poder u órgano reformador de la Constitución como poder constituido se integra a su vez por dos poderes constituidos, a saber: el legislativo y el federativo. Sin embargo, a diferencia de éstos que sí son permanentes, aquél no lo es.

Ahora bien, del hecho de que en el proceso de reforma constitucional participen dos poderes constituidos -el legislativo y el federativo- no se sigue que un poder constituido no los pueda controlar, ya sea el poder judicial, a través de la Suprema Corte de Justicia de la Nación, en funciones de Tribunal Constitucional, o un Tribunal Constitucional como órgano constitucional autónomo. Claro está que en este último caso el argumento resultaría más fácil y hasta más fuerte, porque no se trataría de uno de los poderes constituidos tradicionales -el judicial- controlando al poder u órgano revisor de la Constitución integrado por el legislativo y el federativo, sino que sería un poder u órgano constitucional autónomo el que ejercería el control. Aunado a lo anterior, el poder u órgano revisor, al no ser un poder constituyente sino constituido, tiene límites. Si bien para casi todos los tratadistas el constituyente, al ser originario, no tiene límites, algunos sí sostienen la hipótesis de que hasta un poder constituyente tiene límites. A guisa de ejemplo, el propio Tena Ramírez admite: 1) una limitación inmanente: la finalidad de integrar un sistema u orden jurídico; ${ }^{24}$ 2) limitaciones históricas (o sociológicas): los derechos humanos y la división de poderes; ${ }^{25} 3$ ) limitaciones políticas: los factores reales de poder $^{26}$ y 4) limitaciones internacionales: el derecho internacional, en general, y la internacionalización de los derechos humanos, en particular.

\footnotetext{
${ }^{24}$ "Si el fin de toda Constitución consiste en implantar un orden jurídico, su primera y fundamental limitación la tiene en la determinación de establecer no la anarquía ni el absolutismo, sino precisamente un orden jurídico". (Tena, 1993: 27)

Tena, 1993: 28. Véase : Artículo 16 de la Declaración de los derechos del hombre y del ciudadano de 1789: "Toda sociedad en la cual la garantía de los derechos no está asegurada, ni la separación de poderes establecida, carece de constitución".

${ }^{26}$ "[E]l Constituyente no debe prescindir de numerosos factores políticos, que condicionan el éxito de su obra". (Tena, 1993: 28). Cfr. Lasalle, Ferdinand, ¿Qué es la Constitución?, trad. Wenceslao Roces, Buenos Aires, Siglo XX, 1946, p. 62: "Se cogen esos factores reales de poder, se extienden en una hoja de papel, se les da expresión escrita y, a partir se este momento, incorporados a un papel, ya no son simples factores reales de poder, sino que se han erigido en derecho, en instituciones jurídicas, y quien atente contra ellos atenta contra la ley, y es castigado". (1a ed.: Madrid, Cenit, 1931.)

${ }^{27}$ Tena, 1993: 32-37. Véase la Declaración Universal de los Derechos Humanos de Naciones Unidas y la Declaración Americana de los Derechos y Deberes del Hombre de los países de América, ambas de 1948.
} 
En el caso de México, en relación con la votación calificada de dos terceras partes (de los individuos presentes), es decir el 66.66\%, y la mayoría (simple) de las legislaturas de los Estados, esto es el 50\% más uno, habría que recordar que conforme a lo previsto por el artículo 105 constitucional, para que la resolución de la Suprema Corte de Justicia de la Nación tenga efectos generales en algunos supuestos de las controversias constitucionales y en las acciones de inconstitucionalidad, se requiere de la aprobación de una mayoría de por lo menos ocho votos (de los once ministros), esto es, una votación calificada de $72.72 \%{ }^{28}$ En este sentido, el hecho de que una reforma constitucional sea aprobada por una mayoría calificada no cancela por sí solo la posibilidad de ser objeto de control; bastaría con que la decisión técnica de control constitucional sea adoptada por una votación calificada superior a la de la decisión política.

Por todo lo anterior, consideramos que tanto el procedimiento como el resultado de la reforma pueden ser objeto de control constitucional, siempre y cuando este control sea realizado por un órgano independiente que no participa en el proceso de reforma, y que por ello puede ser imparcial al constatar su constitucionalidad. Con mayor razón si dicho control requiere de una votación calificada superior a la de la propia reforma constitucional para que ésta pueda tener efectos generales.

\section{La tipología de los límites de la reforma constitucional}

La reforma constitucional tiene sus propios límites, además de aquellos propios de la actividad legislativa. En primerísimo lugar se encuentra lo que sería una especie de límite competencial: el poder u órgano reformador de la Constitución está facultado precisamente para ello, i.e. para adicionar o modificar una Constitución, no para destruirla o sustituirla por otra. Al respecto, Emilio Rabasa, en La Constitución y la dictadura (1912), formuló un argumento que mutatis mutandis es vigente hoy en día: la Constitución de 1857, en su artículo 127, autoriza "adiciones y reformas, pero no destrucción constitucional de la Constitución”.

\footnotetext{
${ }^{28}$ Los casos en sí son lo de menos; lo que me interesa es establecer una racionalidad entre la votación calificada requerida para aprobar una reforma constitucional dentro del poder u órgano reformador de la Constitución, de un lado, y para controlar la constitucionalidad de la misma dentro del poder u órgano encargado de hacerlo, del otro.

${ }^{29}$ Rabasa Emilio, La Constitución y la dictadura. Estudio sobre la organización política de México, Porrúa, México, 1990, p. 237. (El énfasis es original.) Cfr. Cajas Sarria, Mario A., "La reforma constitucional: límites de la corte al congreso”, en: Precedente. Anuario Jurídico. 2004, Cali, Facultad de Derecho y Ciencias Sociales, Universidad ICESI, 2005, p. 15: "[E]1 Congreso puede reformar la Constitución pero no le está permitido sustituirla”. (El énfasis es nuestro.)
} 
De igual forma, la tipología de límites de la reforma constitucional comprende una gran variedad de clases o tipos, entre los cuales destacan: ${ }^{30}$

A. Absolutos, impuestos por voluntad expresa del Constituyente y que como tales no se pueden superar al exceptuar un artículo, capítulo o título del ámbito de las reformas; y, relativos, que sí se pueden superar, ya sean: temporales, permitidos después de pasado cierto tiempo desde su promulgación o última reforma; y circunstanciales, prohibidos en determinadas condiciones pero permitidos una vez que éstas ya no están presentes.

B. Autónomos, incluidos en la misma Constitución, como podrían ser las llamadas cláusulas de intangibilidad o cláusulas pétreas; y heterónomos, incorporados por fuentes distintas al propio texto constitucional, como podrían ser los principios generales del derecho o del derecho natural.

C. Explícitos, formulados expresamente en el texto de la Constitución; e implícitos, derivados tácitamente de los anteriores, también conocidos como lógicos.

D. Formales, referidos al procedimiento o la forma; y materiales o sustanciales, relacionados con el contenido o el fondo en sí, también conocidos como axiológicos.

\section{Los límites de la reforma constitucional}

La Constitución mexicana no contiene límites explícitos ni materiales o sustanciales, tales como las cláusulas de intangibilidad o cláusulas pétreas. Tampoco tiene -según la mayoría de los tratadistas- límites implícitos ni formales que se deduzcan o deriven lógicamente de los preceptos y de los principios formulados en la Constitución. No obstante, la Suprema Corte de Justicia de la Nación, al conocer del amparo en revisión, promovido por Manuel Camacho Solís, estableció un importantísimo criterio: "el Poder Judicial Federal, a través del juicio de amparo, sí puede conocer de la constitucionalidad del procedimiento legislativo desarrollado para dar vida a una reforma constitucional". ${ }^{31}$ Con lo cual parece sugerir que el poder u

\footnotetext{
${ }^{30}$ Está más que claro que las tipologías no son exhaustivas sino meramente indicativas. Cfr. Vega García, Pedro de, La reforma constitucional, Tecnos, Madrid, 1985.

${ }^{31}$ Góngora Pimentel, Genaro David, "iPuede plantearse en Juicio de Amparo la inconstitucionalidad del procedimiento de reforma constitucional? (El caso del señor Manuel Camacho Solís)", Lex. Difusión y análisis, 3a época, año III, no. 24, junio, 1997, p. 6. Cfr. Carranco Zúñica, Joel, "El juicio de amparo de Manuel Camacho Solis, un nuevo enfoque constitucional", Revista del Instituto de la Judicatura Federal, No. 7, 2000, pp. 77-125; Arteaga Nava, Elisur, "El amparo Camacho. La impugnación de una reforma constitucional", Alegatos, No. 46, Septiembre-diciembre, 2000, pp. 511-542.
} 
órgano reformador o revisor de la Constitución sí tiene límites implícitos pero, en principio, solamente formales.

Cabe recordar que el 22 de agosto de 1996 Manuel Camacho Solís promovió un amparo para impugnar la reforma constitucional al artículo 122 de la Constitución. Esta reforma incluía entre los requisitos para ser jefe de Gobierno del Distrito Federal uno que le impedía a él contender por dicho puesto de elección popular, al requerir: "no haber desempeñado anteriormente el cargo de jefe de Gobierno del Distrito Federal con cualquier carácter". Por su parte, el 30 de agosto de 1996, el Juez Cuarto de Distrito en Materia Administrativa del Distrito Federal, que por razón de turno conoció del asunto, resolvió, por tratarse de un amparo contra una reforma constitucional, desechar la demanda por ser en su consideración "notoriamente improcedente". Sin embargo, el dolido interpuso la revisión y solicitó a la Suprema Corte que ejerciera su facultad de atracción para resolver dicho recurso. Después de prolongadas y apasionadas sesiones, el 3 de febrero de 1997 la Corte decidió - por una mayoría de seis votos contra cinco- revocar el auto del juez de Distrito y le ordenó examinar la demanda de garantías identificada bajo el expediente 207/96-AUX.

Desafortunadamente, antes de que el juez resolviera el fondo, el juicio de amparo aparentemente se quedó sin materia, ya que en el ínterin se realizó la elección de jefe de Gobierno del Distrito Federal, motivo fundamental por el cual el quejoso había solicitado el amparo y la protección de la justicia federal. Por ello, el juez optó por sobreseer el asunto. Si bien esta decisión puede considerarse como técnica y hasta como adecuada, al hacerlo el juez dejó sin resolver no sólo la cuestión primaria de si procede o no el amparo contra una reforma constitucional sino también la pregunta secundaria: si el juez decide que el amparo sí procede, debería precisar si procede solamente en contra de vicios formales o también materiales. Al respecto, uno de los ministros que formuló el proyecto de la mayoría, al publicar las razones que lo llevaron a votar de esa forma, reconoció: "De ahí que mientras la reforma constitucional no provenga de quien tiene el poder de darla, la reforma es nula y, por tanto, inconstitucional, por violar precisamente las formalidades constitucionales para su expedición". ${ }^{32}$ En otros términos, cualquiera que sea el contenido de la reforma, la Constitución condiciona toda la creación del Derecho, por cuanto no formarán parte del ordenamiento más que las normas material y formalmente acordes con las prescripciones constitucionales. La Constitución opera así un acondicionamiento negativo en cuanto que excluye la posibilidad de que formen parte del ordenamiento jurídico normas que la contradigan.

\footnotetext{
${ }^{32}$ Ibíd., p. 9.
} 
Lo anterior parece sugerir que, al menos para este ministro, el amparo procede contra vicios tanto formales como materiales. Ahora bien, después de citar la fracción I del artículo 103 constitucional: "Los tribunales de la Federación resolverán toda controversia que se suscite: I. Por leyes o actos de la autoridad que violen las garantías individuales", procedió a precisar que esta norma sirve de "fundamento para que a través del juicio de amparo pueda examinarse la constitucionalidad del procedimiento de reforma constitucional". ${ }^{33}$ Cierto es que su argumentación se funda en el hecho de que el silencio acerca de "la procedencia expresa del juicio de amparo en contra del procedimiento de reforma constitucional" no es un "problema insalvable". Para efecto de cubrir esta laguna u omisión, propone reconocer la naturaleza de "ley" en un sentido amplio e incluir en ésta a la reforma constitucional, al realizar primero una interpretación extensiva y luego una integración analógica a la par. ${ }^{34}$ Toda vez que el artículo 70 estipula que "toda resolución del Congreso tendrá el carácter de ley o decreto", resulta incontrovertible que la reforma constitucional como resolución del Congreso tiene la forma de una ley o decreto, y que como tal el amparo es procedente en los términos de la fracción I del artículo 103 de la Constitución, contra leyes -en general-y contra reformas constitucionales -en particular- que violen garantías individuales.

Una vez admitido que la Constitución es una clase de ley y que la reforma constitucional es un tipo de reforma legal, "habría entonces que reconocer que la vía del amparo está expedita para quien sufra una afectación en sus garantías individuales por una reforma constitucional con violación del procedimiento establecido para tal efecto". ${ }^{36}$ A partir de lo anterior, el amparo procede cuando menos por vicios formales o de procedimiento. No obstante, el propio ministro recuerda: "El Tribunal Constitucional es el único órgano constituido que, con el arma de la jurisdicción, puede determinar el contenido de la voluntad del

\footnotetext{
${ }^{33}$ Ibíd., p. 11.

${ }^{34}$ Para reforzar este punto es conveniente recordar que este mismo argumento o razonamiento - a partir de una interpretación extensiva de la palabra 'ley' para abarcar e incluir el vocablo 'constitución' y de una integración analógica a la par, por la identidad de razón, entre la 'reforma legal' y la 'reforma constitucional' - ya ha sido fructífero en el pasado. A falta de mención explícita acerca de quién está facultado para presentar una iniciativa de reforma constitucional, a partir de lo previsto en la fracción F del artículo 72 de la Constitución "En la interpretación, reforma o derogación de las leyes o decretos, se observarán los mismos trámites establecidos para su formación", se aplica supletoriamente el numeral 71 de la misma que establece: "El derecho de iniciar leyes o decretos compete: I. Al Presidente de la República; II. A los diputados y senadores al Congreso de la Unión; y III. A las Legislaturas de los Estados".

${ }^{35}$ Lo anterior sin perjuicio de que el amparo también es procedente, en los propios términos de la fracción I del artículo 103, contra "actos de autoridad que violen garantías individuales".

${ }^{36}$ Góngora, 1997: 11.
} 
constituyente, es decir, puede precisar de manera vinculante y definitiva qué es lo que ha querido decir el constituyente, cosa que no ocurre con ninguno de los demás poderes". Así, estimamos que si la Suprema Corte puede determinar el contenido de la voluntad del poder constituyente, con mayor razón puede precisar la del poder u órgano reformador de la Constitución, el cual es un poder constituido, y como tal podría verificar que el resultado de la reforma constitucional se ajuste a lo dispuesto por la propia Constitución. En este sentido, nos permitimos destacar por lo pronto un par de conclusiones -la segunda y la quinta- del ministro:

Segunda conclusión: Si la reforma constitucional es la manifestación de un poder jurídicamente regulado y sometido a límites (ya sean éstos materiales o formales), el control judicial de la reforma aparece como una exigencia ineludible para garantizar el respeto de esos límites, que no es sino el respeto de la propia normatividad de la Constitución. En efecto, ese control es perfectamente factible ante el órgano jurisdiccional en lo que respecta al procedimiento agravado de reforma. Se trata sólo de un control formal, referente al cumplimiento de los trámites establecidos para la reforma, puesto que dicho procedimiento carece, en principio, de límites materiales. En dicho procedimiento puede intervenir el poder constituyente permanente apartándose de los requisitos y formalidades fijados expresamente en el artículo 135 de la Constitución Federal, dando lugar a alteraciones que provocan auténticas rupturas en el orden constitucional. Si bien, primero, aclara que la reforma constitucional es el producto o resultado de un poder constituido y como tal sujeto a límites, ya sean formales o materiales, luego precisa que en el caso de México, a falta en principio de límites materiales, se trata de un control formal y como tal solamente procede si el poder u órgano reformador de la Constitución se aparta del procedimiento establecido. Y, un poco más adelante, resalta:

Quinta conclusión: La procedencia del amparo que reconocemos, permite que haya reforma constitucional, sí, pero con Constitución. De no realizarse la reforma constitucional conforme a la Constitución, no puede hablarse en puridad de la existencia de un régimen constitucional, sino más bien de un pseudo-constitucionalismo.

De esta manera, para que podamos hablar de un régimen constitucional -y no de una destrucción o ruptura constitucional- es imperioso que las reformas constitucionales sean conforme la Constitución. No obstante, hasta aquí, el control de constitucionalidad -o la revisión de dicha conformidad-no procede necesariamente respecto del fondo o contenido de la reforma constitucional, pero sí al menos de su forma o procedimiento. 
$\mathrm{Al}$ respecto, debemos recordar que la reforma constitucional, como un procedimiento dificultado, parte de las formalidades propias del proceso legislativo ordinario, pero requiere de algunas más previstas en el texto del artículo 135 de la Constitución:

Artículo 135. La presente Constitución puede ser adicionada o reformada. Para que las adiciones o reformas lleguen a ser parte de la misma, se requiere que el Congreso de la Unión, por el voto de las dos terceras partes de los individuos presentes, acuerde las reformas o adiciones, y que éstas sean aprobadas por la mayoría de las legislaturas de los Estados. El Congreso de la Unión o la Comisión Permanente en su caso, harán el cómputo de los votos de las legislaturas y la declaración de haber sido aprobadas las adiciones o reformas.

De este modo, además de las formalidades propias del procedimiento legislativo ordinario -consagradas en los numerales 71 y 72 de la Constitución, tales como la presentación de la iniciativa por las autoridades facultadas para tal efecto, así como la sucesiva discusión y aprobación en ambas cámaras- se requiere de la aprobación por una mayoría calificada de dos terceras partes de los individuos presentes en cada una de las cámaras, de la mayoría simple de las legislaturas de los Estados y, finalmente, el cómputo de los votos y la declaración de haber sido aprobadas las adiciones o reformas.

Lo curioso del caso es que en el amparo de Manuel Camacho Solís, con independencia de que se impugnara algún vicio de procedimiento durante la discusión de la reforma constitucional, lo que se impugnaba en sí era el contenido mismo de la reforma. Ésta le impedía a él acceder a un cargo o puesto de elección popular equivalente a uno que antes no era electivo y que él había ocupado cuando dependía de la designación directa del Presidente de la República. Por esta razón la reforma era violatoria en su perjuicio del derecho de sufragio pasivo, i.e. a ser votado para un cargo de elección popular, consagrado en la fracción II del artículo 35 constitucional. Aunado a lo anterior, el producto o resultado de la reforma constitucional no cumplía con uno de los elementos característicos de una ley, puesto que, además de ser general, abstracta y permanente, debía ser impersonal, en lugar de ser personal y tener un destinatario con nombre y apellido. Igualmente resultaba violatoria del 
principio de irretroactividad al establecer una prohibición ex post facto en perjuicio de una persona.

Por supuesto que si permitimos que las reformas constitucionales se lleven a cabo sin el menor respeto a las formalidades del procedimiento ni a los principios más elementales de racionalidad jurídica, tales como "las leyes implícitas de la legislación" o "la moralidad interna del derecho" y "los atributos esenciales o no-esenciales del buen legislador", no estaríamos ante una reforma conforme a la Constitución sino frente a la destrucción o ruptura constitucional o, como se mencionó anteriormente, un pseudo-constitucionalismo. Lo interesante del caso es que de un vicio en apariencia material superviene uno formal y como tal el amparo es procedente.

Ahora bien, para reforzar cómo a partir de vicios aparentemente materiales supervienen vicios formales y, en consecuencia, la reforma constitucional sí es objeto de control de constitucionalidad, es conveniente traer a colación un caso reciente que se presentó en Colombia y que nos permite examinar tres cosas: ${ }^{38}$ En primera instancia, la Constitución colombiana -a diferencia de la mexicana- reconoce expresamente en su artículo 241 que la Corte Constitucional tiene como función: "Decidir sobre las demandas de inconstitucionalidad que promuevan los ciudadanos contra los actos reformatorios de la Constitución, cualquiera que sea su origen, sólo por vicios de procedimiento en su formación".

En segundo lugar, la aprobación del Acto Legislativo No. 02 del 27 de diciembre de 2004 expedido por el Congreso de la República, el cual aprueba la reelección presidencial inmediata y por lo tanto hace posible una eventual candidatura del actual Presidente de la República, y que además ordena la expedición de una ley estatutaria para garantizar la igualdad en la contienda

\footnotetext{
${ }^{37}$ Considero que la reforma constitucional del 22 de agosto de 1996 es inconstitucional en la parte que requiere "no haber desempeñado anteriormente el cargo de Jefe de Gobierno del Distrito Federal con cualquier carácter". Paradójicamente, en tanto que no se cambie el criterio de "interés jurídico" - y de pasada la relatividad de las sentencias de amparo, la conocidísima fórmula Otero -, los únicos que pueden reclamar dicha inconstitucionalidad para sí serían aquéllos que habían ocupado ese cargo con anterioridad a la reforma y no con posterioridad. Es más, conforme a la doctrina de los actos consentidos, en principio, estos últimos han aceptado tal requisito como parte de las reglas del juego aplicables. Nótese que no quiero decir que el requisito sea constitucional para éstos, sino que tal como están las cosas no tienen interés jurídico en reclamar su inconstitucionalidad.

${ }^{38}$ Véase: Cajas, 2004 (2005): 13-48.
} 
electoral y los derechos de la oposición, vino a reabrir el debate sobre la inconstitucionalidad de una reforma constitucional por otros vicios además de aquellos de procedimiento en su formación.

En tercer término, la jurisprudencia colombiana ha construido, a partir de los vicios de procedimiento, un tercer concepto entre los límites formales y los materiales, a la sazón: los límites competenciales o vicios de competencia. El quid del asunto es determinar si quien ejerce el poder de reforma constitucional se excedió o no en sus facultades reformatorias, i.e. en sus competencias. Si no lo hizo, estamos ante una verdadera reforma de la Constitución. En cambio, si en efecto se excedió, estamos ante una sustitución de la Constitución.

En resumidas cuentas, si bien no se puede demandar la inconstitucionalidad de una reforma constitucional por una violación material, sí es posible impugnarla por un vicio competencial: el poder constituyente autorizó al poder u órgano reformador de la Constitución precisamente para que la reformara, no para que la sustituyera por otra. En otras palabras, una cosa es reformar una parte de la Constitución y otra sustituir un elemento definitorio de la misma.

En el caso concreto, entre otras cosas, además de vicios de procedimiento en sí, se argumentó -y se podría argumentar- que dos principios fundamentales, la garantía de los derechos humanos y la determinación de la separación de poderes, habían sido comprometidos por la reforma. Al permitir una eventual candidatura del actual Presidente de la República para la elección inmediata posterior, se atenta no sólo contra la igualdad en la contienda electoral entre todos los eventuales candidatos a la presidencia sino también contra el régimen presidencial acotado o limitado y el equilibrio de poderes. En pocas palabras, se sustituyó la igualdad en la contienda -a pesar de ordenar la expedición de una ley estatutaria- por la inequidad en la misma y el sistema presidencial con equilibrio de poderes por un presidencialismo más fuerte sin tantos equilibrios. Aunado a lo anterior, consideramos que el actual Presidente de la República, el cual fue electo para un solo período sin posibilidad de reelección inmediata, no se puede ver beneficiado por una aparente reforma constitucional que implica una sustitución de la misma. Sobre todo porque ésta violenta, más que el principio de irretroactividad, la división temporal del poder, al permitir que, a través de una eventual candidatura a la presidencia, el actual Presidente pueda extender su permanencia y hasta perpetuarse en el poder, en especial dada la sospecha de inequidad en la contienda electoral. 
La cuestión es que la reforma constitucional no cumplió con uno de los elementos característicos de una ley, puesto que, además de ser general, abstracta y permanente, debía ser impersonal, en lugar de ser personal al tener un destinatario con nombre y apellido. De tal suerte, para que la reforma fuera constitucional bastaría con introducir la reelección presidencial inmediata, pero estipulando que ésta no podría entrar en vigor para la elección siguiente sino para una subsiguiente, con lo cual se aseguraría su impersonalidad.

\section{Conclusión}

Para finalizar, solamente nos resta hacer explícitas nuestras conclusiones ya implícitas. En primer lugar, la reforma constitucional es una forma de legislación, es decir, una especie de un género, y como tal está sujeta a los mismos límites que el resto de la formas de la legislación. En segundo lugar, las reformas constitucionales cuentan con límites implícitos, los cuales, si bien no son necesariamente materiales, sí al menos son formales, hecho que ha dado lugar al reconocimiento de límites competenciales o vicios de competencia.

\section{Bibliografía}

Arteaga Nava, Elisur (2000), "El amparo Camacho. La impugnación de una reforma constitucional", Alegatos, No. 46, Septiembre-diciembre, 2000.

Atienza, Manuel (1989), "Sociología jurídica y ciencia de la legislación", en: Bergalli R. (ed.), El derecho y sus realidades. Investigación y enseñanza de la sociología jurídica, PPU, Barcelona.

Atienza, Manuel (1989), "Contribución a la teoría de la legislación”, Doxa, Vol. 6, 1989.

Atienza, Manuel, "Reasoning and Legislation", en: Witgens, Luc J. (ed.), The Theory and Practice of Legislation. Essays in Legisprudence, Aldershot, Ashgate, Hampshire, 2005.

Bobbio, Norberto (1971), "Le bon législateur", en : Hubien, Hubert (ed.), Le raisonnment juridique/Legal Reasoning/Die jurisdiche argumentation, Bruxelles, Établissements Émile Bruylant.

Cajas Sarria, Mario A. (2004), "La reforma constitucional: límites de la corte al congreso", en: Precedente. Anuario Jurídico. 2004, Cali, Facultad de Derecho y Ciencias Sociales, Universidad ICESI, 2005.

Carranco Zúñica, Joel (2000), "El juicio de amparo de Manuel Camacho Solis, un nuevo enfoque constitucional", Revista del Instituto de la Judicatura Federal, No. 7, 2000. 
Flores, Imer B. (2003), "Constitución, democracia y derecho: teoría constitucional y valores constitucionales", Revista del Instituto de la Judicatura Federal, No. 15, 2003.

Flores, Imer B. (2004), "Assessing Democracy and Rule of Law: Access to Justice", en: Peczenik, Aleksander (ed.), Proceedings of the $21^{\text {st }}$ IVR World Congress, Lund (Sweden), 12-17 August, 2003, Part I: Justice, Stuttgart, Franz Steiner Verlag, 2004.

Flores, Imer B. (2005), "Heráclito vis-à-vis Parménides: Cambio y permanencia como la principal función del derecho en una democracia incipiente", en: Molina Piñeiro, Luis, J. Fernando Ojesto Martínez y Fernando Serrano Migallón (coords.), Funciones del derecho en las democracias incipientes. El caso de México, Porrúa y Facultad de Derecho UNAM, México.

Flores, Imer B., "Legisprudence: the Forms and the Limits of Legislation", ponencia presentada en el Special Workshop Legisprudence, en el XXII IVR World Congress en Granada, España, del 24 al 29 de mayo de 2005.

Flores, Imer B. (2005), "The Quest for Legisprudence: Constitutionalism v. Legalism", en: Witgens, Luc J. (ed.), The Theory and Practice of Legislation. Essays in Legisprudence, Aldershot, Ashgate, Hampshire.

Flores, Imer B. (2006), "Apuntes para una teoría - y práctica - del derecho judicial: Algunas reflexiones críticas sobre técnica jurídica", Reforma judicial. Revista Mexicana de Justicia, No. 7, enero-junio, 2006.

Fuller, Lon L. (1968), "Implicit Elements in Made Law", en: The Anatomy of Law, Frederick A. Praeger, New York.

Fuller, Lon L. (1969), The Morality of Law, $2^{\text {a }}$ ed., New Haven, Yale University Press.

Fuller, Lon L. (1981), “The Forms and Limits of Adjudication”, en: The Principles of Social Order, Duke University Press, Durham, North Carolina.

Fuller, Lon L. (1999), "The Case of the Speluncean Explorers", Harvard Law Review, Vol. 112, No. 8, 1999.

Góngora Pimentel, Genaro David (1997), “iPuede plantearse en Juicio de Amparo la inconstitucionalidad del procedimiento de reforma constitucional? (El caso del señor Manuel Camacho Solís)", Lex. Difusión y análisis, 3a época, año III, no. 24, junio, 1997.

Hart, H. L. A. (1961), The Concept of Law, Oxford University Press.

Hart, H. L. A. (1983), "American Jurisprudence through English Eyes: The Nightmare and the Noble Dream", en: Essays in Jurisprudence and Philosophy, Oxford, Clarendon Press.

Kelsen, Hans (2001), La garantía jurisdiccional de la Constitución. (La justicia constitucional), trad. Rolando Tamayo y Salmorán, Universidad Nacional Autónoma de México. 
Lasalle, Ferdinand (1946), ¿Qué es la Constitución?, Siglo XX, Buenos Aires.

Rabasa, Emilio (1990), La constitución y la dictadura. Estudio sobre la organización política de México, Porrúa, México.

Schmitt, Carl (1931), La defensa de la Constitución. Estudio acerca de las diversas especies y posibilidades de salvaguardia de la Constitución, trad. Manuel Sánchez Sarto, Editorial Labor, Barcelona.

Tena Ramírez, Felipe (1993), Derecho constitucional mexicano, Porrúa, México.

Vega García, Pedro de (1985), La reforma constitucional, Tecnos, Madrid.

Zagrebelsky, Gustavo (1997), El derecho dúctil. Ley, derechos, justicia, Madrid, Trotta. 